\title{
La poesía vasca de la segunda mitad del siglo $\mathrm{XX}$
}

\author{
Patricio Urquizu
}

(UNED)

Tras la guerra civil del 36 los primeros libros de poesía en euskera se editaron en México y Santiago de Chile y es en Guatemala y Biarritz donde Jokin Zaitegi publicó la revista cultural y literaria vasca más relevante de la posguerra: Euzko Gogoa [Espíritu Vasco] (1950-1959)'.

Murieron en el exilio poetas como Telesforo Monzón (Bergara, 1904Baiona,1981), autor de Urrundik [Desde lejos] (México 1945), y Gudarien egiñak [Los hechos de los gudaris] (Biarritz, 1947); Pedro Ormaetxea (Etxano 1891-Viña del Mar, Chile, 1949), autor de los poemarios Ipuintxoak [Cuentitos] (Santiago, 1947), y Bigarren ipuintxoak [Los segundos cuentitos] (Santiago, 1948), así como Toribio Etxebarria (Eibar, 1887-Caracas, 1968), cuyos poemas titulados Ibiltarixanak [Poemas del caminante] se publicaron un años antes de su muerte en Zarautz, cuyo prólogo en castellano dice:

Toda la vida me ha tentado el atavismo de las razas trashumantes que sin duda duermen en el fondo de nuestro ser. Antes de la primera guerra mundial, cuando no habia aún pasaportes ni visas, solía divertirme alarmando a la familia con un plan de ir a pie hasta Vladivostok. Pero, bromas aparte, la verdad es que siempre he envidiado a los que han hecho de la vida un eterno vagar, aunque marcharon sin alforjas y sin dinero ${ }^{2}$.

Dejemos a estos poetas transterrados en su duro vagar americano y volvamos a los que tuvieron que sufrir el largo exilio interior. Y vamos a empezar este nuevo viaje presentando a

Juan Mari LEKUONA. Nacido en Oiartzun (1927), pequeño pueblo guipuzcoano en la frontera con Navarra y el País Vasco-Francés, siguiendo la vía de su tío Manuel Lekuona, escritor y poeta reconocido, inicia su itinerario poético con Herenegun. Zazpi poema [Anteayer, Siete poemas, 1950], y con una

1 Patricio Urquizu, «La cultura del exilio vasco en eusquera», J. L. Abellán et al., Memoria del exilio vasco. Cultura, pensamiento y literatura de los escritores transterrados en 1939. Biblioteca Nueva. Madrid, 2000, pp. 99-146.

2 Patricio Urquizu, art. cit., p. 128. 
frase latina: Invisibilia enim Ipsius, a creatura mundi, per ea quae facta sunt conspiciuntur.

En este primer ensayo poético religioso de Lekuona se pueden vislumbrar además de las influencias del triunvirato de la preguerra, - Orixe, Lizardi y Lauaxeta--, las dos fuentes principales donde bebió constantemente a través de toda su vida, la Biblia y la poesía popular, a las que sumó una sensibilidad especial para contactar con la Naturaleza. Dios se muestra en la Natura y el poeta se basa en élla para llegar a Él.

Lekuona inició su camino poético en la revista Egan (1949 ss), que fue dirigida inteligentemente por Luis Michelena durante todo el franquismo dentro de la línea posibilista que los tiempos y la censura permitían ${ }^{3}$, y publica en 1966 Mindura gaur [El dolor hoy], en plena crisis de la conciencia cristiana en el País Vasco, y constata Jainkoa il da biotz askotan 'Dios ha muerto en muchos corazones'. En este librito mecanografiado aparecen poemas como Meretriz illa 'La meretriz muerta' y Porlandi, poemas que reflejan las preocupaciones sociales del momento.

En 1973 publica Muga beroak [Fronteras cálidas], donde recoge los poemas anteriores en distinto orden iniciando con el poema Aize errota 'Molino de viento'. Ya no aparece en su obra el optimismo inicial sino un pesimismo cuyos ecos ya se oyen en el Apocalipsis, 18, 22: No se escuchará ya más en ti el sonido del molino. Es una segunda fase de su obra en la que bajando del caserío a la ciudad se hace solidario de los seres más humildes. Otros tres poemarios son los que completan su obra: Hondarrean idatzia [Escrito en la arena] (1972), Argiaren eskolan [En la escuela de la luz] (1979), y Mimodramak eta ikonoak (1990).

En unas jornadas de Verines planteaba de este modo su poética:

Siempre he creído que el mensaje del poeta debe ser paradójico. Por tanto, nunca me ha gustado expresar directamente que intento salvar el euskara, que me duele mi pueblo, que apuesto por la modernidad, que me desmarco del XIX, ni que voy a hacer Iglesia, pero tendré en cuenta no decir tampoco lo contrario, para no contradecirme con aquellas connotaciones que mi historia personal entraña y sugiere. De ahí que mi poesía lejos de situarse por encima de las contingencias, quiere responder al sentir colectivo desde la ausencia presentida, desde la nada estrictamente calculada, desde el vacío de elementos controvertidos, directamente expresados.

$Y$ no escojo entre mis símbolos la cruz, el martillo, el libro o la alambrada, sino que prefiero aquellos otros de tierra, agua, fuego, aire; o mano, cabellera, estatua de carne, rostro... He apostado por una visión elemental de lo humano, no exenta de metafísica, como protección espiritual de la sensibilidad, tan explotada y tan maltratada a veces en el mundo exterior e interior de cuantos en mi tierra convivimos ${ }^{4}$.

3 Joan Mari Torrealdai, La censura de Franco y el tema vasco. Premio Ciudad Irun 1998. Kutxa, Donostia 1999.

${ }^{4}$ Juan Mari Lekuona, «Temas y estructuras», El estado de las poesías. Los Cuadernos del Norte. Caja de Ahorros de Asturias. Oviedo 1986, p. 140. 
Empieza, pues, Lekuona a trabajar con los elementos fundamentales - tierra, agua, aire y fuego- y a preguntarse sobre la esencia del hombre. Ya su obra viene a adquirir una dimensión más antropológica que social. Al igual que en Zulaika, como señala Joxe Azurmendi, el hombre tiene un valor más cósmico que social, prometeico u homérico, sabiendo que como señala Teilhard de Chardin, para comprender el alfa y el omega el hombre es esencial, estando Dios en ambos puntos.

En La escuela de la luna ocuparán la cinematografía Bergmaniana y los elementos corporales un gran espacio, pero no a través del lenguaje expresionista ni del pesimismo kierkegaardiano sino de la esperanza cristiana. Nos habla de una nueva liturgia, de todos los detalles de una ceremonia que tiene claras semejanzas con la obra Liturxia do corpo (1976) de Arcadio López Casanova. Las imágenes de la Salomé bíblica se mezclan con el canto gregoriano, las señoritas de Avignon picassianas con el vientre vacío de los Apóstoles de piedra oteizianos.

Finalmente en Mimodramas e Iconos, nos habla de la génesis de los miedos y de la galería de las sombras en un retomar constante de las preguntas fundamentales y sobre todo la primera, qué es el hombre vasco en la dialéctica materia-espíritu, bajo la luz de las experiencias estético-antropológicas de Oteiza y Barandiarán.

Sintetizando, pues, el itinerario poético de Lekuona, éste no es sino una búsqueda constante de la Belleza a través del Hombre.

En esta línea religiosa con aportaciones particulares se hallan otros poetas como el benedictino Xabier Diharce «Iratzeder», los franciscanos Manex Erdozaintzi, Salbatore Mitxelena, y Vitoriano Gandiaga entre otros, el capuchino Inazio Goikoetxea «Gaztelu», el carmelita y director de la revista de poesía Olerti (1959-1995) Santiago Onaindia, el sacerdote Nemesio Etxaniz, etc.

Cuando el año 1964 Juan San Martín (1922-2005), tambien poeta, consulta al profesor Luis Michelena sobre qué autores considera dignos de introducir en la antología que se halla preparando la respuesta del mejor conocedor del momento de la literatura vasca es la siguiente:

En una antología de este tipo incluiría a los recién muertos como muestra de las viejas tendencias: Orixe y Oxobi. De los actuales son indispensables Aresti, Gandiaga, Mirande e Iratzeder. Luego entre los de nuevas tendencias a Lasa, Otsalar (pseudónimo de J. San Martín) y Peillen; alguien me ha comentado que Azurmendi ha escrito algún que otro poema hermoso, pero no lo conozco sino como prosista. Habrá más nuevos pero no los conozco, ya que Olerti sólo leo de vez en cuando. Finalmente los de estilo clásico: Nemesio (Etxaniz), Erkiaga, el joven Lekuona, Gaztelu... Desde el punto de vista formal pocos hay de la calidad del Padre Iraizoz. Y te atreverias a prescindir de Onaindia y Zaitegi? ${ }^{5}$

5 Patri Urkizu, Koldo Mitxelenaren euskal gutunak (1951-1984). Bilduma 19, Errenteria 2004, p. 164 . 
Cinco años más tarde, el 1969 publicaba San Martín la primera antología de la poesía de la postguerra que nombró Nueva $\mathrm{Ola}^{6}$ en la que presenta a 24 poetas, algunos más de los señalados por Mitxelena.

Ibon Sarasola ${ }^{7}$ recoge en su antología poética de la postguerra que va del año 45 al 64 y que publica el 73, seleccionando no a los mejores sino a los más interesantes en su opinión a 18, entre los que se hallaban los ya mencionados más Monzón y Krutwig entre otros.

Krutwig y Mirande suponen el inicio de la heterodoxia poética vasca, con poemas publicados en los años 50 en la revista Euzko Gogoa, ya que proclaman la ruptura del pareado euskaldun / fededun, vasco y cristiano, para posicionarse en líneas budistas, no religiosas o antirreligiosas, paganas y panteistas.

Jean MIRANDE (Paris 1927-1972), escritor vasco nacido en la capital francesa, hijo de padres suletinos, después de dedicar toda su vida, breve pero intensa al aprendizaje de múltiples lenguas, sobre todo las célticas y el euskera, escribió en ésta poemas, narraciones, algunos ensayos, hizo algunas traducciones y finalmente se suicidó la navidad del 72 .

En un artículo que escribe Andima Ibiñagabeitia en Euzko Gogoa ${ }^{8}$, al comentar uno de los poemas de Jon Mirande dice lo siguiente: (Traduzco)

Mirande en cambio, anda por los caminos de la poesía moderna. Agudo, fino y sonoro, de sus poemas emana una dulce armonía aunque sólo las mentes y los oídos muy finos pueden captarla. Bastante surrealista, sus pensamientos no son fáciles de asir. Aun con todo tenéis un bello poema en "Oroituz» (Recordando).

Michelena, por su parte, autor de una de las historias de la literatura vasca más concisas y exactas lo define así:

Mirande, traductor de Poe y Fafka ha dado ya, a pesar de su juventud, abundantes pruebas de su inquietud y de su falta de respeto para con los convencionalismos, al tiempo que ha acreditado como poeta de gusto seguro y cultivado y como versificador de consumada habilidad .

El «corpus poeticum» de Mirande es reducido. 69 poemas, mientras no aparezcan más, y aunque ha sido editado varias veces, carece de una edición crítica adecuada, aunque ya ha sido traducido al castellano por Felipe Juaristi ${ }^{10}$.

Pertenecen al año 53 exactamente tres documentos claves para entender la poética del escritor vasco parisino. El primero es el del prólogo que escribió a

6 Juan San Martín, Uhin Berri [Nueva ola] 1964-1969 bilduma. Sociedad Guipuzcoana de ediciones, Donostia, 1969.

${ }^{7}$ Ibon Sarasola, Gerraondoko Euskal-Poesiaren Antologia (1945-1964). Lur, Donostia, 1973.

${ }^{8}$ Andima Ibiñagabeitia, «Euzkadiko Irratirako», Euzko Gogoa, 1. Urtea, 1950, n. 11-12, p. 53.

${ }^{9}$ L. Michelena, Historia de la literatura vasca, Madrid, Minotauro, 1960, p. 160.

10 Jon Mirande, Ilhun-argiak. Claroscuros. Ed. de F. Juaristi. Zarautz, UPV, 1992. 
una selección de poemas que recopiló con la intención de editarla en Caracas. En él se defiende de los ataques que ha sufrido por sus «poemas panteístas», contestando que sus poemas no los ha compuesto por el bien moral de nadie, sino por simple solaz $\mathrm{y}$ «for the happy few», para que los degusten unos pocos.

El segundo documento es la entrevista que le hace Andima Ibiñagabeitia en su piso de París para Radio Euzkadi, y que se titula «Olerkarienean» (En casa del poeta $)^{11}$. Aquí hace un repaso de sus filias y de sus fobias. Por supuesto, Lauaxeta y Zaitegi se hallan entre las primeras, y habla también de cómo ha hollado tierras vírgenes todavía no andadas por poeta vasco alguno, como los mitos celtas, la masturbación, la paidofilia, el lesbianismo, etc., etc., lo cual no tenía nada de raro, ya que hasta entonces la mayoría de los poetas vascos había pertenecido al clero. Pero lo que más se subraya del joven poeta, aparte la calidad innegable y la belleza de sus poemas, es su autenticidad, lo extraordinariamente veraces y apasionados que resultan sus poemas.

El tercer documento es el titulado «Liburu Lizunetaz» (A propósito de los libros pornográficos $)^{12}$. Aquí arremete contra la vigencia del binomio «Euskaldun-fededun» (Vasco y con fe), es decir, católico, apostólico y romano, considerando que entre los vasquistas y nacionalistas del momento se podían hallar perfectamente tanto panteístas como neopaganos, mahometanos y ateos, y que por supuesto el bautismo no tenía nada que ver con la vasquidad.

Mirande, pues, se considera al margen de la sociedad de los «buenos vascos» practicantes, e integrante del grupo de los heterodoxos, entre los que podríamos citar a Federico Krutwig, Dominique Peillen o Gabriel Aresti, pero con los cuales tampoco comulga ideológicamente.

Estos cuatro autores son los que tras beber en las corrientes ya clásicas, ya vanguardistas europeas dejarán una amplia obra, que rompe con los moldes literarios anteriores.

Aresti, por ejemplo, dedica su primer y mejor libro titulado Maldan Behera (Cuesta Abajo $)^{13}$ a Jean Mirande y lo inicia con una cita de Nietzsche, autor también preferido por el parisino, que le dedicó un ensayo, por desgracia perdido.

Peillen y Mirande, ambos hijos de suletinos, crean en su exilio parisino el año 1962 una revista literaria, para poder escapar de la censura tanto nacionalista como franquista, y la titulan Igela. Euskaldun heterodoxoen errebista (La rana. Revista de los heterodoxos vascos) ${ }^{14}$. Se trata de una especie de álbum diverso donde se mezclan manifiestos poéticos y políticos, colecciones de refranes, parábolas, y cuentos, y que logró la participación de autores de este lado de los $\mathrm{Pi}$ rineos como Irigoy, Juan San Martín, etc. Veamos lo que dice la revista en su presentación en castellano.

$"$ Andima Ibiñagabeitia, "Olerkarienean». Gernika, 1953, n. ${ }^{\circ} 23$, pp. 98-102.

12 Euzko Deya, n." 355, 1953.

${ }^{1.7}$ Euskera, Bilbao, 1960, pp. 7-52.

14 IGELA, Euskaldun heterodoxoen errebista, 1-6. París 1962-1963. Reedición, Zarautz, Lur. 1979. 


\section{UNA REVISTA SATIRICA EN VASCUENCE: IGELA}

(Len eta azkena erderaz)*

En la vieja estampa sonríe maliciosamente Erasmo. Se puede oír el reír de Rabelais. Hoy día, cuando tenemos la cabeza hecha un bombo por el ruido de las doctrinas y el gritar de los militantes, el recuerdo de los humoristas y satíricos puede salvarnos. Así haremos en IGELA, ayudándonos de Erasmo, A. Jarry, O. Wilde, Curros Enríquez y B. Shaw; pero de ningún modo haremos propaganda política o religiosa...

* Primera y última en castellano.

Hoy podemos leer en vasco y en castellano sus poemas así como su novela La Ahijada, especie de Lolita vasca, censurada durante tiempo, y de cuyos avatares como de la clave más precisa y detallada de sus poemas podemos encontrar en los epistolarios de él mismo ${ }^{15}$, de Ibiñagabeitia ${ }^{16}$ y de Michelena. ${ }^{17}$ También podemos encontrar sus traducciones de Nietzsche, Lorca, Poe, Crosby, Keats, Pennaod, Hofmannsthal, Kafka, Schiller y Txernikhovski con la versión original en una reciente edición. ${ }^{18}$

La evolución ideológica de Mirande es muy rápida desde un cristianismo crítico hacia un nacional-socialismo y la prédica de la violencia, de la que pronto se arrepiente como indica en una carta escrita a su amigo íntimo Ibiñagabeitia en abril de 1956: ha sido una estupidez predicar la violencia a los vascos, ir como hijo desleal contra la madre Iglesia y querer inculcar en el blando corazón de mis paisanos los conceptos vitales de los salvajes de Germania. Me arrepiento de ese pecado - mea maxima culpa - y no lo quiero volver a repetir.

En noviembre del 70 cuando visita la Casa Vasca de París y escucha a un joven marxista de ETA predicar la otra nueva buena, ya no se siente solidario ni con las viejas ni con las nuevas generaciones e indica que pueden construir sin él lo que en palabras de Shakespeare sería The State of Euzkadi.

De naturaleza enfermiza y pesimista se suicida con barbitúricos y wisky al final del año 1972, pero dejando una de las obras más modernas y sugerentes en vasco.

Gabriel ARESTI (Bilbao 1933-1975), hijo de familia humilde, de padre franquista y madre nacionalista, consiguió el título de perito mercantil y trabajó como contable en empresas de Laudio, Eibar, Baracaldo y Bilbao. Afirmándose frente a su padre inició el estudio del euskera en plan autodidacta a los doce años, con un método hiperpurista titulado, Método gradual para aprender el

15 Patri Urkizu (ed.), Jon Miranderen gutunak (1948-1972), Susa, Zarautz, 1995.

${ }^{16}$ Patri Urkizu (ed.), Andima Ibiñagabeitia. Erbestetik barne-minez. Gutunak (1935-1967). Susa, Zarautz, 2000.

${ }_{17}$ Patri Urkizu (ed.), Koldo Mitxelenaren euskal gutunak (1951-1984), Bilduma 18. Errenteriako Udala, 2004, pp. 13-225.

${ }_{18}$ Patri Urkizu (ed.), Jon Mirande orhoituz (1925-1972). Diputación de Gipuzkoa, Donostia, 1997. 
Euzkera. Se perfeccionó con los carmelitas de Begoña, y ya el año 1953 comenzó a relacionarse con autores que escribían en la revista Euzko Gogoa. Participó en las tertulias literarias de La Concordia junto con Ramiro Pinilla, Angel Ortiz Alfau, Sabina de la Cruz...Y de esta primera época es su amistad con Agustín Ibarrola, Blas de Otero, Gabriel Celaya y Curros Enriquez.

Ideológicamente de izquierda, nunca fue del Partido Comunista, por considerar que el posicionamiento de dicho partido con respecto a Euskadi era sumamente centralista. Y como señala Koldo Izagirre ${ }^{19}$, fue un gran poeta y agitador, que tampoco perdonaba a la burguesía abertzale su falta de compromiso con el euskera.

Empezó traduciendo a Boccaccio, Shakespeare, Baudelaire, Tomas Meabe, Juan Ramón Jimenez, Bertold Brecht, Nazim Hikmet, y a su amigo Blas de Otero. Y pronto consiguió ser premiado por sus poemas: Premio Loramendi por Maldan behera [Pendiente abajo] (1960), Premio Orixe por Harri eta Herri [Piedra y pueblo] (1964), que a su vez recibió el Premio Nacional de poesía Iparragirre (1968)...

Maldan behera es un largo poema de 1904 versos donde hace una incursión simbolista de la mano de Mirande y Nietzsche. El superhombre baja del monte a la ciudad pasando por Hariztia 'El robledal' (Aresti), Lizardia 'El fresnedo' (Lizardi), Iratze ederra 'El hermoso helechal' (Iratzeder), y Loremendia 'El monte de flores' (Loremendi ${ }^{20}$ ) es decir, tres etapas del devenir histórico del hombre vasco representados en tres poetas para acabar en él. Y nos encontramos que ya en esta obra aparece cierta fe en la revolución, en la fuerza liberadora del Logos, cuya misión fundamental es desalienar al hombre. En contra de todos los fatalismos sociales y políticos aparece en Aresti la fe en el hombre y su futuro.

Harri eta Herri es considerada como la obra cumbre de la poesía social vasca, y el inicio de una nueva era en su literatura. Fue la obra poética más leída en aquellos años del tardofranquismo. Muestra de su éxito fue su consagración con el Premio Nacional. Amigo de Oteiza y de la obra Los Apóstoles de piedra en el Santuario de Aranzazu, bastión de la resistencia vasca, nos hablaba de que era un lapidófilo, y así sus obras poéticas posteriores al Harri eta Herri llevarán este leit motiv en el título, de lo que no es ajena la admiración que sentía por los poetas Cabral de Melo, Drummond de Andrade, Celso Emilio Ferreiro y su Longa noite de pedra (1962). Euskal Harria 'Piedra vasca' (1967), Harrizko herri hau 'Este pueblo de piedra' (1970), y el Azken harria 'Última piedra' (1976) póstumo, son otros tres poemarios en los que bajo dicho símbolo va recogiendo sus últimos poemas, ya un tanto pesimistas a la vista del vacío que le iban haciendo tanto los abertzales conservadores como los autodenominados de la izquierda abertzale.

19 Koldo Izagirre, «Mudos blus de la nada (De la última poesía vasca: repaso urgente)», Incursiones en territorio enemigo. Pamiela, Iruñea, 1997, pp. 33-69.

${ }^{20}$ Loramendi es el capuchino Joakin Bedoña (1907-1933) en cuyo honor se hace el certamen en el que participa Aresti y cuya obra Olerki ta idatzi guziak [Poemas y otros escritos] se publicó en 1960 . 
Resumiendo. La poética arestiana se simboliza en la piedra, en aquellos vascos de piedra blindada que citaba Miguel Hernández, y como observaba Jon Juaristi la primera poesía de Arana, la de Unamuno y la de Aresti concidían en una misma estructuración del contenido: un rayo que cae sobre un árbol sagrado, que a su vez deja a la intemperie al poeta, voz del pueblo.

Este tipo de poema - señala $\operatorname{Kortazar}^{21}$ - concibe el Paraíso terrenal utópico bajo el árbol de Gernika. En un tiempo pasado el hombre vasco poseía los bienes de toda utopía: felicidad, igualdad y bondad. Pero esta concepción del nacionalismo peneuvista no casa con la ideología arestiana. Y la piedra se convierte en un símbolo alternativo al árbol. La Edad de Piedra donde el País Vasco fue comunista y feliz, y que a su vez Aresti desea proyectar en el futuro: un mundo mítico y utópico. Frente a la ironía y la desesperanza de Mirande se alza la fe en el progreso de Aresti.

Finalmente murió, joven, demasiado joven, a los 42 años tras una operación de estómago. Dejaba tras de sí una inmensa labor de pionero, creador, polemista y animador de nuevos escritores del grupo Lur (Ramon Saizarbitoria, Arantxa Urretabizkaia, Ibon Sarasola, Xabier Kintana, Patri Urkizu, Anjel Lertxundi, Mikel Azurmendi...) recogida en diez volúmenes por la editorial Susa (1986).

Tuvo una ristra de seguidores la poesía social arestiana, en su vertiente humanista existencial como señala Maribel Sanchez ${ }^{22}$ al hablar de la poética de Xabier Lete. Con éste y con Mikel Arregi, autor de un único poemario y de las letras del cantante Imanol llegó la poesía existencialista a su cumbre en opinión de Izagirre ${ }^{23}$.

Es larga la lista de poetas social-cristianos, social-realistas, o simplemente políticos. Y como ya hemos indicado más arriba en la antología de 69 de San Martín aparecían poemas de veinticuatro poetas, que luego el tiempo con más o menos (in)justicia ha ido descanonizando o reubicando a cada uno en su sitio.

Merecen mención también aunque aquí sea sólo eso: Mikel Lasa (Donostia, 1938), lector de Rimbaud y Rilke y autor de una obra poética breve pero densa; Joxan Artze (Usurbil 1939), autor de una obra muy personal, collage de poesía visual, social y religiosa; y Jose Anjel Irigaray (Donostia, 1942), autor de cuatro poemarios donde cristaliza temas de la mitología vasca, griega y de la modernidad.

Los últimos años del franquismo y los iniciales del postfranquismo fueron ricos en experiencias literarias. Se sentía una necesidad vital de estar al día, de crear algo nuevo. Y como señalaba José Azurmendi ${ }^{24}$ en la revista Oh Euzkadi, un espíritu libre y desenfadado ha entrado en nuestra literatura. Gracias, evidentemente a la labor pionera de Mirande y Aresti.

21 Jon Kortazar, «La poesía vasca actual», El estado de las poesías, Los cuadernos del Norte, 3, Oviedo 1986, pp. 132-138.

${ }^{22}$ Maribel Sanchez, «Leteren poetika», Gaurko poesia, Labayru, Bilbao, 1993, pp. 95-127.

${ }^{23}$ Koldo Izagirre, «Txipitasunaren iraultza», Gaurko poesia, Labayru, Bilbao, 1993, pp. 55-71.

24 José Azurmendi, «100 urte Apollinaire eta hizkuntza berrizte literarioa». Oh Euzkadi, n. ${ }^{\circ} 6$, Donostia, 1980. 
En las capitales fueron creándose grupos que editaban sus revistas literarias vascas, la mayoría de vida efímera. Así en Donostia surgía bajo la dirección de Ramón Saizarbitoria y Koldo Izagirre la revista Ustela (1975-1976), en Bilbao la revista Pott (1978-1980) y en Bayona la revista Maiatz (1982...) que aún dura...

Las reuniones tabernarias de la parte vieja bilbaina en las que se juntaban Ruper Ordorika, Bernardo Atxaga, Jimu Iturralde, Jon Juaristi, Manu Erzilla y Joseba Sarrionaindia engendraron a Pott, cuya editorial decía que no se hallaba al servicio de nadie, ni de ninguna política sino únicamente para aclarar nuestras mentes. De todo este grupo es evidente que el de mayor proyección en el mundo de las letras es Bernardo Atxaga, que publica el año 1978 un poemario titulado Etiopia, considerado por algunos críticos como Kortazar ${ }^{25}$ el inicio de una nueva etapa de la poesía vasca. La renovación a través de la ironía que supone el juego Utopía / Etiopía, y de un objeto patchwork, conjunto de narraciones cortas y poemas, donde los personajes desvalidos encuentran la simpatía del autor, que prefiere el mundo de los antihéroes.

Indica Izagirre también acertadamente en el artículo mencionado que Etiopía es un libro paradigmático en el que el estudio del poeta no es la ciudad sino el mundo. Su lugar de trabajo abarca el mundo entero, donde todas las ciudades tienen cabida, y en cuya geografía ideal también la tienen las literaturas de todas las naciones.

En los párrafos siguientes intentaremos acercarnos a la poesía y obra de Sarrionaindia, autor menos conocido que Atxaga.

Joseba SARRIONAINDIA (Iurreta 1958), inicia desde muy joven su obra literaria escribiendo sobre cine y literatura en las revistas Zeruko Argia y Anaitasuna. Profesor de Fonética en la UNED de Bergara, el año 80 gana el premio R.M. Azkue con su obra Izuen gordelekuetan barrena [A través de los laberintos del miedo] que publica al año siguiente. Es en la cárcel de Carabanchel donde acaba el prólogo de la edición de este poemario. Se trata de un Cuaderno de vitácora, utilizo sus propias palabras, que supone un viaje a través de siete territorios: Sorterria [Tierra natal], Paris, Grecia, Lisboa, Irlanda, Praga, y Deserria [Destierra]. En cada uno de ellos homenajea a sus escritores preferidos: Kavafis, Kafka, Pessoa... por lo que el crítico Kortazar lo considerará como poeta perteneciente a la corriente metaliteraria. Sin embargo Izagirre nos recuerda las palabras del mismo Sarrionaindia a propósito de su propio modo de hacer literario:

Por otra parte, mucho se habla sobre esta literatura. Que no se entiende, que es dificil, y a ver para qué o para quién escribimos. Si alguien me preguntase para quién escribo, quizá le respondería que para los amigos. Pero puedo decir - sin temor a faltar a la verdad, si es que existe - que para otros muchos. Puedo decir: para los que alguna vez se han colgado cerezas en las

25 Jon Kortazar, Literatura vasca desde la transición. Bernardo Atxaga. Ediciones del Orto. Madrid 2003. 
orejas, para los capitanes de enmastilados barcos, para los tocados por el amor y los violines nocturnos, para el flautista inventor de un nuevo color. Puedo decir: para los que he sentido cercanos en el peligro aún no creyendo demasiado en el hacha y la serpiente, para los que defienden las Termópilas aún sabiendo que ha nacido Efialtes, para los dos bellos ojos que me aguardan, para los que la fortuna no les es favorable. Puedo decir también: para el mago Merlín preso en la cueva, para el espantapájaros que saluda sonriente al amanecer, para los desesperados habitantes de las prisiones, y para los luchadores de todas las causas perdidas.

Me estoy alargando en este prólogo, y me pregunto si no será por la carcelitis u otra enfermedad parecida. Pero estamos en huelga de hambre, han torturado hasta la muerte a Joseba Arregi, y surgen demasiadas, estériles reflexiones si se está quieto ${ }^{26}$.

Desde la cárcel sigue editando poemas y ensayos, y tras su fuga de la cárcel de Martutene ya en el exilio publica el poemario titulado Marinel Zaharrak [Viejos marineros] (1987) donde recoge su obra anterior y 35 poemas escritos en la cárcel. Aquí ha pulido, eliminado y creado nuevos poemas.

Para entender la atmósfera de crítica y censura del mundo literario vasco contaré una anécdota personal. Eva Forest directora de la editorial Hiru donde da a conocer traducciones de autores vascos me pidió un prólogo para el ensayo de Sarrionaindia Ni ez naiz hemengoa 'No soy de aquí'. Trabajé en el estudio de la obra sarrionaindiana y tras enviarlo a Forest su contestación fue en carta de primero de diciembre de 1994 'Tu prólogo es muy bueno, muy documentado, un trabajo notorio que no iba a pasar inadvertido' por ello lo vetó y salió la traducción con el prólogo de otro poeta: Edorta Jimenez.

Mi estudio acaba tras criticar la defensa de la lucha armada que se hacía en dicha obra con una cita de Ernesto Sábato: Ya no se puede dudar, después de terribles experiencias: el fin no justifica los medios, y es trágicamente ilusorio perseguir fines nobilísimos con medios innobles ${ }^{27}$.

Este poeta exiliado es también un caso paradigmático, ya que sus obras, sigue publicando con asiduidad aunque me atrevería a señalar que se le nota la distancia del país--, en un momento en el que la poesía vasca no se vende nada en el mercado sus obras son best-sellers en la feria de Durango.

Para seguir con detalle la poesía de los 80 y los 90 podemos ojear las páginas del grueso volumen (más de 600 páginas) de Jon Kortazar, Luma eta Lurra. Euskal poesia 80ko hamarkadan [Pluma y Tierra. La poesía vasca en los 80] (Labayru, 1997), y cosa no extraña la obra titulada en gallego y editada en Galicia A ponte das palabras. Poesía vasca 1990-2000.

En la primera analiza Kortazar en cinco apartados (1. La poesía de la banda Pott, 2. La poesía de la experiencia, 3. La poesía del País Vasco-Francés, 4. El

${ }^{26}$ Koldo lzagirre, art. cit., pp. 12-13.

27 Ernesto Sábato, Apologías y rechazos. Seix Barral, Barcelona, 1979, p. 163. 
grupo de la revista Susa, y 5 . Trece poetas (Patxi Ezkiaga ${ }^{28} \ldots$...), una bibliografía general con las críticas de cada obra pormenorizadas, así como la lista anual de las obra poéticas editadas, que vienen a ser aproximadamente una al mes.

En la segunda aparecen una serie de veinte autores más o menos jóvenes que no hemos ni siquiera mencionado en esta introducción general -mea culpa-, pero el tiempo y el espacio no me dan lugar para presentarlos siquiera someramente. Daremos de todos modos sus nombres: Pako Aristi, Aurelia Arkotxa, Rikardo Arregi Diaz de Heredia, Gari Berasaluze, Harkaitz Cano, Isabel Diaz, Igor Estankona, Martin Etxeberria, Mirari Garcia de Cortazar, Karlos Linazasoro, Gerardo Markuleta, Miren Agur Meabe, Juanjo Olasagarre, Xabier Olaso, Jose Luis Padron, Asier Serrano, Castillo Suarez, Kirmen Uribe, Urtzi Urrutikoetxea y Juan Luis Zabala.

Evidentemente hay muchos más poetas y sobre todo en el momento actual poetisas vascas, pero sólo menciono a once de éstas, - hamaika en euskera significa innumerables-: Arantxa Urretabizkaia, Teresita Irastorza, Marijose Kerexeta, Miren Agur Meabe, Amaia Lasa, Itxaro Borda, Henriette Eire, Aurelia Arkotxa, Aintzane Galardi, Sonia Gonzalez... cuyo estudio bien podrían servir para analizar el pensamiento poético de la mujer vasca actual.

Para finalizar este prólogo quiero decir algunas palabras de Izagirre, editor entre otras obras de la colección de poesía vasca del siglo $\mathrm{xX}$ más completa, $X X$. Mendeko Poesia Kaierak ${ }^{29}$, donde recoge en libritos de medio centenar de páginas a los en su entender cuarenta mejores o más interesantes poetas éuskaros del siglo, pero al no autoincluirse hemos de reparar en algun modo esta injusticia.

Koldo IZAGIRRE (Donostia, 1953), es poeta, narrador, guionista y director vasco de cine, traductor de Castelao, Manuel María, Uxio Novoneira, Maiakovski, Papasseit, etc., colaborador en revistas como Zeruko Argia y Anaitasu$n a$, creador de la revista Ustela, y editor de los citados cuarenta cuadernos de la poesía del siglo $\mathrm{XX}$.

Los títulos de sus poemarios son: Itsaso ahantzia 'Mar olvidado' (1976), Oinaze zaharrera 'Al viejo dolor '(1977), Guardasola ahantzia 'El paraguas olvidado' (1978), Balizko Erroten Erresuma 'Tierra de molinos imaginarios' (1989) y Non dago Basques 'Harbour’ ‘Dónde está Basques’ Harbour? (1997), Rimmel (2007).

${ }^{28}$ Patxi Ezkiaga (Legorreta, 1943), estudió literatura en las Universidades de Oxford y Cambridge, y es autor de una obra prolífica. Felipe Juaristi lo define como «El poeta que explora la existencia" y sus libros de poemas han sido recogidos con traducción al castellano en: Patxi Ezkiaga, Haize Hurbila 'Viento cercano'. EHU, UPV, Zarautz, 1994, 888 pp.

${ }^{29}$ Los poetas antologados son: Orixe, Lizardi, Lauaxeta, Zaitegi, Salbatore Mitxelena, Xabier Diharze, Nemesio Etxaniz, Jon Mirande, Juan Mari Lekuona, Manex Erdozaintzi, Gabriel Aresti, Bitoriano Gandiaga, Joxe Azurmendi, Mikel Lasa, Jose Angel Irigaray, Joxan Artze, Amaia Lasa, Arantxa Urretabizkaia, Bernardo Atxaga, Joan Mari Irigoien, Joseba Sarrionaindia, Jose Luis Otamendi, Tere Irastorza, Rafa Egiguren, Xabier Montoia, Joseaustin Arrieta, Itxaro Borda, Koxan Muñoz, Juan Kruz Igerabide, Omar Nabarro, Patziku Perurena, Felipe Juaristi, Iñigo Aranbarri, Jon Arano, Luigi Anselmi, Karlos Linazasoro, Luis Berrizbeitia, Pako Aristi, Juanjo Olasagarre y Rikardo Arregi Díaz de Heredia. 
Iñaki Aldekoa ${ }^{30}$ en su Antología de la Poesía Vasca, donde selecciona a once poetas, cataloga tanto a Izagirre como a Sarrionaindia como los representantes de la Poesía Militante, considerando que en la poética de ambos subyace claramente un ataque contra la literatura burguesa o traidora, y siendo la factura de los poemas en Sarrionaindia de tipo directo y los de Izagirre de clave alegórica.

Esta clave alegórica supone un nuevo lenguaje, como ya señalaba Lete en la aparición de Itsaso Ahantzia. Un lenguaje lleno de elipses y alusiones, casi críptico, que exige en sus primeras obras sobre todo un lector esforzado y conocedor tanto de la literatura y la historia vasca como universal.

Estilo rupturista que ha hecho escuela en los poetas de la revista Susa - Gorka Arrese, Iñigo Aranbarri, Omar Nabarro, Jose Luis Otamendi, Xabier Montoia...-, donde se pasa del surrealismo a la denuncia descarnada, del intimismo y automatismo a los mundos marginales otrora y hoy tan vigentes del rock duro.

Evidentemente no están aquí señaladas todas las tendencias de la poesía vasca de la segunda mitad del siglo Xx, y probablemente nos hemos olvidado de muchos autores importantes que exigirían una mayor atención, pero dados los límites de esta somera exposición quede para otra ocasión el estudio más detallado de las corrientes poéticas más holladas por los poetas vascos de diversas generaciones que publican formando un mosaico ecléctico y hoy conviven en paz y guerra.

\title{
ANTOLOGÍA BILINGÜE
}

\author{
Juan Mari LEKUONA
}

\section{SAN MARTIN TXIKI}

Oilarite bisigotikoak, zaldi-ferrazko leihotik, argi gorriz keinatzen zuen, eta peristefanon martiri kantua aletzen.

Zenobioko kutxan gorderik jakinduria: larruzko kodexaren etimologiak. Ahozaho zebilen, errepika akonpasatuan, hamabi zenbakien ritornello druidikoa.

${ }^{30}$ Iñaki Aldekoa (ed.), Antología de la Poesía Vasca. Euskal Poesiaren Antología. Visor, Madrid, 1991. Los poetas seleccionados de esta antología ya hace tiempo agotada son: Jon Mirande, Gabriel Aresti, Mikel Lasa, Ibon Sarasola, Juan Mari Lekuona, Koldo Izagirre, Bernardo Atxaga, Joseba Sarrionaindia, Felipe Juaristi, Iñigo Aranbarri y Xabier Lete. 
Santu mozorrotuak -mozorro santutuak

heroiaren ausardiaz ostu zizkion

geinuari, gaztain hostoen-arketipoa,

sorogiroen egutegia, eiheraren ardatz zurajea.

Lazaretoa eraikitako ongile hark

iragon zuen jentil herriko zubia, sendatuz

hango izurritea, ekarriz urrea

eta garia. Erromatar gudari hark,

kapa erdibanatzean, hona mimodramaz

gauzatu parabola xumearen mami ugaria.

Absidean dirau, bizi-zuhaitzak inguratua, trogloditen bisaiaz, zaldizkoen ajedrezatuaz, purpurazko kaliza dirdaitsu eskuan.

\section{SAN MARTÍN TXIKI}

La visigótica aurora amagaba,

desde la ventana en herradura, rojos destellos

y desgranaba el peristéfanon del canto martirial.

Sabiduría atesorada en el cofre del cenobio.

Etimologías en códices de pergamino,

Corría de boca en boca, acompasado repique,

el ritornello druídico de los doce primeros números.

El santo disfrazado —el disfraz santificado-, con audacia de héroe, robó al genio el arquetipo de las hojas del castaño, el calendario de las mieses, el maderamen motriz del molino.

Aquel bienhechor que construyó el lazareto franqueó el puente de los gentiles, acabando con la peste reinante, y trayendo consigo oro y trigo. Aquel soldado romano, al compartir la mitad de su capa, esceníficó así con un mimodrama el contenido rico de una parábola sencilla.

Continúa en el ábside, rodeado del árbol de la vida, con su rostro troglodita, el ajedrezado de los caballeros, y el cáliz de púrpura resplandeciente en sus manos. 


\section{ATARRABI}

Estasiaren gainezkaldian, leihoteria gotikoek

Su hartu zuten, mihi eta hosto

kausituz, brodadura biribil simetrikoetan.

Grialak, zaldunen ontzi mistikoak, afariaz zekarren oroigarri esmaltatua. Zazpi ahizpei irrifarra loratu zitzaien ezpain hertsien tolestura orribikoetan. Eta erromes zihoan herria, galtzadetan gora, altzairu finezko lauzak oinkatuz.

Eskola-nabusiek Salamonen eztia dekretaleen orrazetan abaraskatu zuten zuhurtasunez. Jakintsuen itzalok harrigarriago irudikatzen ziren jendeen fantasian.

Deabruaren kobalagun, ongiaz eta gaizkiaz jakitun. Noiznahi, noranahi, joateko ahalez. Ekaitzen kudeatzaile. Gero, hildakoan, ez zuten beleek jan, usoek eraman baizik. Itzal hegozuri, esaera zaharren koilarea lepotik, ipuinez mozorrotu zen dorretxeetako zuhurtziaren birrete beltza.

En el rebosar del éxtasis, los ventanales góticos ardieron, convirtiéndose en lenguas y hojas los arcos simétricos de los bordados.

El Grial, cáliz místico de los caballeros, ofrecía el memorial esmaltado de la cena. Floreció la sonrisa de las siete hermanas en los pliegues bifoliados de sus apretados labios. Y el pueblo iba en peregrinación, calzada arriba, pisando losas de fino acero.

Los catedráticos de hora destilaron con prudencia la miel de Salomón en los panales de las decretales. $Y$ las sombras de estos sabios se proyectaban prodigiosamente en la fantasía de las gentes.

Compañero de cueva del diablo, conocedor del bien y del mal, poseía la facultad de ir en todo momento a todo lugar. Embridaba las tempestades. Luego, al fallecer, no lo devoraron los cuervos: lo transportaron las palomas.

Sombra de albas alas, llevaba al cuello un collar de refranes y el negro birrete de la prudencia que moraba en las casas torre adoptó forma de leyenda. 


\section{III}

\section{BERETERRETXE}

Haritzetik eskegi zuten zalduna. Biluzik. Ai-hotsak altzairu, zarratatu zen gauaren tenpluko isila. Orbelak lurrera: odol-hustuaren azken arnasen dardara. Borreroek atorraz garbitu zituzten eskuak, eta erdibanatu - banderizoen harrapakinarrano beltza eta damaren eraztuna. Hiru ezpatek zulatu zuten amaren bihotza.

Zaldi-trostan ilunbekoen parada. Zerraldoa bidegurutzean utzia. Goizalbaz lore gorriz estali zen maiteñoaren leihopea. Negarretan zegien hots bazko-oilariteak.

Gerokoan, bide-ertzean zut, hilarria. Artesau enblematikan, tenk geziak, esanahitsu argizagiak: galdu zutena nola prest zegoen, etxearen alde, gau eta egun, zuhurtziaz eskaintzeko bere bizia.

Haren khantorea zen iruleen eresi guzizkoena. Lihoaren neke-penetan - oihal zurian beren semeez ohartuz - emakumeentzat zin egitea bezala zen faltsuki erailaren kantua.

\section{BERETERRETXE}

Colgaron al caballero de un roble. Desnudo, Ayes de acero desgarraron el silencio del templo de la noche. Hojas secas caían al suelo: temblor en los últimos estertores del exangüe.

Los verdugos limpiaron sus manos en su camisa y se repartieron - botín de banderizosel águila negra y la sortija de la dama.

Tres espadas traspasaron el corazón de la madre.

El cortejo de los hijos de la oscuridad se alejó al trote.

El cadáver quedó abandonado en la encrucijada. Al alba brotaron flores rojas bajo la ventana de la amada. El alba pascual se deshizo en llanto.

Más tarde, a la vera del camino, levantaron la estela funeraria. En emblemática artesanal, las flechas tensas, elocuentes las luminarias: cómo aquel, a quien habían eliminado, estaba dispuesto a ofrecer, día y noche, y con toda generalidad su propia vida en defensa de la casa. 
Fue su romance la elegía preferida de las hilanderas. Mientras realizaban las penosas labores del lino - el recuerdo de los hijos indeleble en las telas blancas-fue como un juramento para aquellas mujeres el canto del que ejecutaran a traición.

\title{
IV
}

\author{
AXULAR \\ Haize erauntsiak -manierismo pentekostalak- \\ bihurritu zituen erretauletako jantzi hegalak. \\ Hitza ere, pulpituek ospez landu zuten, \\ erretorikan torniatuz mintzo barrokoa. \\ llunek eta argiek, kontraste bortitza zegiten \\ lauki katartikoen ezin-kabitu hanpatutik. \\ Orduetako katedradunek, salmantikoen os- \\ karbian, zorrozten zituzten gaubeleen begiak. \\ Hitz eta esaldi —zutabe eta moldura - bazuen \\ mintzagai ederrik. Baina Erdi Aroko lati- \\ na, euskal moldetara isurtzean, baxuerliebe \\ bihurtu zuen lekuko mintzairaren arkitekturan. \\ Eromenaren enbata bazterretan. Airetik \\ ekarritako gazteak, zapoak zaintzen \\ akelarretan. Eta inkisizioko jujeek, \\ gaizkiaz itsuturik, herriratu zuten gar- \\ tzelik, heriotzarik, sorgin prozesuen patologian. \\ Idazleak berak etsaiarena omen jakinduria. \\ Doktoreek, ordea, arrazoitan oretu zuten \\ kantiken eta liburu aszetikoen garia. \\ Lau orpoetan tinkatu zituzten etikaren ateak.
}

\section{Axular}

El embate del viento - manierismo pentecostal-arremolinó los flecos de los ropajes en los retablos. Hasta la palabra fue trabajada con distinción por los púlpitos, torneando con retórica el discurso barroco.

Los claro-oscuros ofrecian recio contraste desde la henchida inabarcabilidad de catárquicos lienzos. Catedráticos de horas aguzaban, en el cielo estrellado de los salmanticenses, los ojos de las aves nocturnas. 
Palabras y frases —columnas y molduras-lograban asi hermosas pláticas. Pero convirtió el latín medieval, en bajo relieve al verterlo en molde vasco, en la arquitectura del habla local.

Galernas de locura por doquier. Jóvenes transportados por los aires cuidaban sapos en los aquelarres. Y los jueces de la inquisición, cegados por el mal, trajeron cárceles y muerte con sus patológicos procesos de brujería. Se cuenta incluso que el escritor adeudaba al diablo su sabiduría.

Pero los doctores amasaron con razones el trigo de los cánticos y libros ascéticos. Fijaron sobre cuatro quicios los portones de la ética.

\section{$\mathbf{V}$}

\section{BERDABIO}

Urkatuaren agurrak — kantu eta elegiharrenik hunkitzen zuen bihotza, gerrondotako sutondoen behar gorrian.

Herio zigorrak penatu zuen auzoa.

Ordainetan, oroipenaren berri zaharrek, eraldatu zuten zigortuaren kondaira, omenka ederretsiz menditar tristea.

Urre altxorra inguruan omen etxetik: oilarrak jotzean, ardiek belarra jaten diharduten azpi hartan.

Elizetan ere urrea ebasten omen, gero, urtu eta, moldetaritzan antzatzeko diru berri galgarria.

Eta presondegian, kantuz atera omen bizitzako odol tanten negar ozpina, urteak egun adinbat bertsotan.

Eskarmentagarri hil zuten. Haren zaldiak - atzitu ezinak - lau hankak omen xuriak. Hesian galdu zen. Borreroak hexurrezko xirula kraskatu zuen, urka estutzean. 


\section{BERDABIO}

La despedida del ajusticiado - canto y leyenda- afectaba al corazón en sus fibras más sensibles, en la miseria de los hogares de posguerra.

La pena de muerte acongojó al vecindario. A cambio, las antiguas noticias guardadas en la memoria sublimaron la historia del condenado, dignificando con fabulaciones al triste montañés.

Hablillas de que guardara tesoros cerca de casa: allá donde las ovejas, al cantar el gallo, acostumbran a pacer.

Hablillas de que robara oro hasta en las iglesias, para, después de fundirlo, falsificar en moldes el dinero nuevo de su perdición.

Hablillas de que en la cárcel hubiera convertido en romance, tantos versos como años, el llanto acre de las gotas de sangre vividas.

Lo ajusticiaron para escarmiento ajeno. Su caballo, inaprensible, dicen que tenía blancas sus cuatro patas. Cayó en el cercado. El verdugo quebró una flauta de hueso al estrujar la horca.

\section{Jon MIRANDE AYPHASORHO}

\section{OIANONE}

Gelan sarthu ginenean Gauerditan, ilhunean, Mundua egin zan mutu Zuten izarrek kantatu Biok etzan ginenean.

Oianone! Oianone!

Gau hunetan zaitut ene; Larru legun eta zuri, Bulhar samur, sabel guri, Nire neska Oianone.

Ezti bakhanez bethea Zure matxantto maitea Urtzen zan ene ahora, Zabalik ore antzera Eta gozokiz bethea. 
Zure baratzeko borthan

Arrotz batek jo du. Bertan

Sarbidea emaiozu

Zama baithakar pisu,

Ez dezazula utz borthan!

Gauko oihanetan lasterka

Zure gainean zaldizka,

Behor zalhu eta bizkor,

Gau bideeetan gaindi, mozkor

Banaramazu lasterka.

Ezpain likhits, esku lizun,

Atseginetan jakintsun

Bulharretik belhunera

Haragi biok ikhara,

Jauzten zaitut, neska lizun!

Hiltzen naizela dirudi:

Batetan mila su-ziri

Ene burmuinetan sarthu...

Botz-uhinak uzten gaitu

Hilik garela irudi.

Egin du irri Ilhargiak;

Hesten zaizkiola begiak

Neskatilak erraiten dau

Esker onetan othoitz haur,

Dantzularik Ilhargiak:

«Gora izan hadi, Suge, Hi haizenik ene Rege, Hi haizenik ene Jainko

Gau huntan eta bethiko,

Urrhe-buztaneko Suge!

Hathorkit berriz laztanik;

Janhari gozo ba dut nik

Ene baratzean are

Ezti gehiagorik Hire

Bil ezak berriz laztanik».

Suge laztana nekhatu

Zan ordea... loak hartu...

Ezti loreetan etzanda

Atseden hartzen ari da,

Gaizoa baita nekhatu. 
Ene maitea, moxu bat

Has dezantzat bertze hainbat!

Sugea baitatza lotan

Indarren bihurtzekotan

Oi! emaiozu moxu bat...

\section{OIANONE}

Desde que nos metimos en la habitación

En la medianoche y a oscuras,

Enmudeció el mundo,

Cantaron las estrellas

Cuando nos acostamos.

¡Oianone! Oianone!

Eres mía esta noche;

Tu piel es como una olorosa azucena,

Tus pechos tiernos, tu vientre blando.

¡Ay, mi chica Oianone!

Tu jardín de las delicias

Destilaba dulce savia,

Abierto como un gladíolo,

Lleno de penetrante perfume,

Conocía mi suave boca,

Ha golpeado la puerta del mismo

Un ser extraño. No te demores,

Dale asiento,

Que viene muy cargado,

¡No lo dejes en el umbral!

Como en los oscuros parques,

Cabalgando sobre tu torso,

tu yegua ágil y turgente,

En las encrucijadas nocturnas, ebrio

Me llevas y no puedo parar.

Labios lúbricos, manos viajeras,

Doctora en placeres,

Desde la cabeza a los pies,

Casi agonizando de placer,

Como dos temblorosos montes.

Parece que muero;

Mil antorchas encienden

$Y$ queman mis sentidos... 
Olas de gozo nos abandonan,

Casi desfallecidos.

Ha reido la Luna;

Como si se te cerraran los ojos,

Dice la muchacha

Entre susurros esta oración,

Y escucha atenta la Luna,

«Álzate, Serpiente,

Que tú eres mi Rey,

Que tú eres mi Dios,

Esta noche y para siempre

¡Serpiente de dorada cimera!

- Vengan de nuevo caricias;

Caigan pétalos de rosas

En mi jardín de las delicias.

Vengan de nuevo caricias

Que dulcifiquen mis humedades.

Mas, al final, se cansó

La Serpiente, y durmió,

Tumbada entre olorosas flores

Duerme un grato sueño,

Descanso del héroe.

¡Amor mío, dame un beso,

$Y$ que le sigan mil más!

Ya que duerme la Serpiente

para que se vuelva potente

;Ay, dale un beso...!

\title{
OHIKO JAINKOARI
}

\author{
Eli, Eli \\ lamma-sabakthani?
}

Josu bar-Joseph, Nazarethen zinaudelarik

Tenplu-heipean itzal eta hitz emaiten,

Oi zergatikan hor etzaitu judu zar batek

Judako zuhain gazte hori, jo'ta moztu!

Josu bar-Joseph, ebili naiz zure elizetan

Ezkoen suan bihotz sor haur sutu nahiz, 
Nuen orduon, Rabbi, zure baithan sinhesten

(Eta ondikotz! aingeruen baithan ere...)

Josu bar-Joseph, ikasleak zurekin ziran

Zuk ereitean nola gari goi-elheak

$\mathrm{Ni}$ ere izan nauzu mintzo nire anaiei;

Bainan anaiok erran dute hitz haur: «Ertzo».

Josu bar-Joseph, badut othoi egin gauerdiz, Argizagia begi makhur so zan etoi

Eta zuk aldiz utzi nauzu... Zergatik arren?

Zergatik arren, on hotsezko jainko Josu?

Josu bar-Joseph, badut burhau' in zuri aitzi:

bihotzean osk bainituen zazpi ziraun

Zeure munduon soilik nago - edozein zakhur

Zoriontsuago bizi da ni bainoago.

Josu bar-Joseph, deithu zaitut haizeen artetik, Hilbeltz erdiko gauhil hartan zurtz eta zut, -Argizagia ezpain hertsi parrez zegoen Zeure zerutik deus ez duzu ihardetsi.

Josu bar-Joseph, gaztaroan maite zindudan.

Maitakeri hark noradino nau iroan...

Gaur, judu-seme, gutartera itzul bazinde,

Gurutzifika zindezaket nik ostera.

\title{
AL DIOS DEL LUGAR
}

\author{
Dios mío, \\ ¿ por qué me has abandonado?
}

Josu bar-Joseph, que estabas en Nazareth,

$Y$ hablabas y forjabas tu fama en el pórtico del templo,

Lástima que no hubiera un viejo judio que te golpeara

$Y$ cercenara de raíz el joven y prometedor tronco de Judá.

Josu bar-Joseph, yo que he frecuentado tus Iglesias,

Consolando al calor de las velas este frío corazón,

En ti creía entonces, Rabino

(Y desgraciadamente también en los ángeles...)

Josu bar-Joseph, tus discípulos te acompañaban allí donde fueras,

$Y$ tú sembrabas, como si fueran trigo, palabras, y te entendían.

También yo me he acercado a mis hermanos,

$Y$ ellos me han pagado con insultos y denuestos. 
Josu, bar-Joseph, he rezado al amor de la noche;

Aviesa, la luna inclinaba su único ojo polifemo hacía mí,

$Y$ tú, sin embargo, me has abandonado. ¿Por qué?

¿Por qué tú, Dios Josu, que eres bondad infinita?

Josu bar-Joseph, he blasfemado y maldecido tu imagen,

Siete víboras me roían el corazón,

Estoy solo en el mundo, cualquier perro

Alcanza la felicidad antes que yo.

Josu bar-Joseph, erguido en pie y huérfano, en una noche Muerta de enero,

He hecho oír mi voz por entre el susurro del viento

La luna limitaba con los labios cerrados-

Nadie ha respondido desde tu cielo.

Josu bar-Joseph, te amé en mi juventud.

¿Y a dónde me ha llevado tal amor...?

Si hoy volvieras entre nosotros, vástago de judios,

Sería yo mismo quien te crucificara de nuevo

\section{III}

\section{ORTZIREN ZALDUNEN GUDU KANTA}

Ortzi jainkoen Jauna, kasta goihen Aita, zaitzagula zuzenez onhets eta maita. Etsaien oinpetzekotz ordua jin baita, borroka bortitz hontan iguzu garhaita.

Nahiz hautsiak izan Zure aldareak gaitzets ez gaitzazula gu bekatoreak: berreraikiren ditu gure adoreak, berriz izanen dira gainean loreak.

Zure herria zenak ukatu bazaitu, Goizerriko zitalak gaixtarazi baitu, geure karra bederen ezin da hamaitu, Zure zaldunak gara, haidor eta haitu.

Harzara bozten gaitu Ortziren izenak, lurraren gaztaroan Haren haur ginenak: entzun itzazu, jauna, gure boz ozenak, berriz ere kantatzen azali lehenak.

Luzaz egon da lurra Zu itzul haiduru; gaur eguzki zaharrak, eginik inguru, 
lehen bezain gorririk eman du leinhuru. Agur Ortziren soa, zeruko Lauburu.

Otso-eme higuinak egozten du hagun, Ortziren atabala delakotz ezagun: haren hiltzeradino guduka dezagun, haren beldur ez izan Ortzi deno lagun.

Lo zen Herensugea jaunak iratzarri eta Bere -eskuinean hura du ezarri, kristar okelez gose, odolez egarri, datorren hilketari egin du batzarri!

Belar tzarra bezala Ortziren aihotzak Trenkatzen 'tu etsaiak, egoizten hil-hotzak; ez ditu lagunduren jaungoiko arrotzak, landa gizenduren du gizonen gorotzak.

\section{CANCIÓN DE GUERRA DE LOS CABALLEROS DE ORTZI}

Ortzi, señor de los dioses, padre de los superiores, sea tu voluntad aceptarnos y amarnos, Porque ha llegado la hora de aplastar a los enemigos, en esta dura lucha venga de tu mano la victoria.

Aunque un día fueron rotos tus altares, no nos abandones a nosotros pecadores. los levantaremos de nuevo con nuestras propias fuerzas, habrá de nuevo flores adornándolos.

Sabemos que te ha negado el que fuera tu pueblo, lo ha echado a perder el veneno de la esperanza, mas no se ha extinguido nuestra pasión, somos tus caballeros, fieros y escogidos.

Por ello nos emociona el nombre de Ortzi a los que en la juventud de la tierra fuimos sus niños. Escucha, Señor, nuestras voces sonoras cantando nuevamente los primeros himnos.

La tierra ha esperado largo tiempo tu vuelta; el viejo sol, tras su travesía, ha brillado con tanta fuerza como antes. Albricias a la mirada de Ortzi, símbolo del cielo.

A la temible mujer-lobo se le hace la boca agua, Porque es conocido el sonido de Ortzi; 
peleemos hasta su muerte,

no tiemble quien sea amigo de Ortzi.

Ha despertado al Dragón que dormía

y lo ha sentado a su diestra,

hambriento de carne cristiana, sediento de su sangre,

se halla preparado para el próximo banquete.

El cuchillo de Ortzi corta a los enemigos

como si fueran mala hierba, los deja muertos;

no les han de ayudar los dioses extraños,

el estiércol de los hombres alimentará la tierra.

IV

EUSKALDUN ZINTZOEN BALADA

(Aldi berean Ortzi euskal jainkoari zuzendu gabe othoitz bat dena, zintzo ez den batek eginik.)

Soin zabal, zalhu, txapeldun, Euskaldun eta Fededun,

- Handi baita - sudur mintzo,

Zintzo dira, o! hain zintzo

Eta barnez oro zaldun...

...Nahiz arrunt den azala

(Izaitetik hek bezala

Ortzi Jaunak zaint'nazala.)

Ilhunpean zeuden lehen

Bainan JEL argia goihen,

- Jautsi baita Euskadi-ra,

Argiturik bizi dira

Ahalikan eta zeheen

Demokrat onen gisala.

(Argitzetik hek bezala

Ortzi Jaunak zaint' nazala.)

Jakintza badute anhitz,

Atso--, haur, eta zuhurt-hitz,

Badakite politika,

Pilota, dantza, kantika,

Bai eta kantu ez likits-,

Leitzen dakite Misala.

(Leitzetik heiek bezala

Ortzi jaunak zaint 'nazala.) 
Trebe izaki tekhnikan, Joritzen dira Amerikan; Haatik, han ere zintzoki Elkartzen dira Batzoki

Abertzaleetan; ez bakan Joaiten, han ere, elizala. (Joritzetik hek bezala Urtzi jaunak zaint' nazala.)

Aphezak eta auzaphezak Benedikatu ezkontzak Egiten dituzte bethi Onetik landa hobeti Dastatzekotan - aratzak Diren neskekin, ontsala. (Ezkontzetik hek bezala Ortzi jaunak zaint 'nazala.)

Bainan ahanzten zitzaitan Hospatzea neurthitzotan Heien jaunzdura jathorra:

Ongi zuritu athorra Dute jaunzten igandetan, Bihotzaren zuriz ala? (Zuritzetik hek bezala Ortzi jaunak zaint' nazala.)

\section{IGORTE:}

Nola, juduen baitzinen Zintzo diren Euskaldunen, jaun zara, Jahve, gisala Neu, zer ere zaitan jinen. Zintzotzera hek bezala Ortzi-k utzi ez nazala.

\section{LA BALADA DE LOS BUENOS VASCOS}

(Que es al mismo tiempo una oración al dios vasco Ortzi, de alguien que no es demasiado fiel.)

Tiene ancho el cuerpo, ligero, lleva boina, Vasco en palabras, dechado de fe,

- Que es grande-, lo proclama su nariz, $Y$ son tan buenos, joh tan buenos! ¡Y tan caballeros desde la cuna!

¡... Aunque cualquiera lo diría fijándose en su piel! 
(Guárdeme, Señor Ortzi,

De ser como ellos.)

Vivían como el hombre de las cavernas,

Pero hete aqui que se hace la luz

Y baja a Euskadi JEL, la luz más brillante,

$Y$ desde entonces viven iluminados,

Tan constreñidos como se pueda esperar

De los demócratas formales.

(Guárdeme, Señor Ortzi,

De ser iluminado como ellos.)

Tienen mucha sabiduria

Señoronas, niños y máximas,

Saben de política,

Pelota, danza, canto,

Y también cancioncillas sinsorgas.

Saben leer el Misal.

(Guárdeme, Señor Ortzi,

De leer como ellos.)

Son hábiles en cuestiones técnicas,

Hacen su agosto en América;

Sin embargo, alli también como buenos chicos

Se reúnen en Batzokis

Abertzales; van a la iglesia,

Alli también, en compañia.

(Guárdeme, Señor Ortzi,

De enriquecerme como ellos.)

Sacerdotes y alcaldes

Bendicen siempre

Aquellos sus matrimonios

Para que puedan saborear

Lo mejor de lo mejor

De sus limpias muchachas.

(Guárdeme Señor Ortzi

De casarme como ellos.)

Casi se me olvidaba

Celebrar en versos

Su vestimenta tan natural.

Visten blanquísima camisa

Los domingos y fiestas de guardar.

¿Acaso piensan blanquear su corazón?

(Guárdeme, Señor Ortzi,

De blanquearme como ellos.) 
POSTDATA

Tal y como eras de los judíos, asi eres. Jahvé, señor de los vascos que son buenos. $Y$ por lo que pueda suceder quiera Ortzi que no me dé por ser tan bueno como ellos.

\section{V \\ ORHOITUZ}

Zaldi beltzak irrintzika zeuden.

Sutan ziran inguruko zelhai gorak. Hartzen genduen atseden, alhargunen intziriez alai.

So ziraden, bekhaitz, saiak oro giza-hiroz ok egin beharrez. Garoetan neska sabel naro zaurituen odola nigarrez...

Gau joriak zithal hotz zerion geure bihotz-min-gai 'ta zorion orhoitua gizaldiz gizaldi.

Lagun! Hilkar-lore-baratzetan genbiltzanok, ilhargi zuritan noiz dukegu, diztirant, Eguerdi?

\section{RECORDANDO}

Encabritados relinchaban los negros corceles. Acometía el fuego la campiña cercana.

Sacudiamos la fatiga, el lamento de las viudas era a nuestros oidos canción alegre.

Arrogantes miraban los buitres, ahítos de carroña humana, a punto de reventar. Entre los helechos sangraban copiosamente las muchachas de las heridas infligidas a sus vientres desgarrados.

En las noches frías y plenas la felicidad renuevan nuestros doloridos corazones recordada por los siglos de los siglos. 
Los que como nosotros caminan, ;Amigo! bajo el claro de luna en los jardines de la muerte ¿volveremos acaso a ver el sol de mediodía?

\section{GABRIEL ARESTI}

Nire aitaren etxea defendituko dut. Otsoen kontra, sikatearen kontra, lukurreriaren kontra, justiziaren kontra, defenditu eginen dut nire aitaren etxea.

Galduko ditut aziendak, soloak, pinudiak; galduko ditut korrituak, errentak, interesak, baina nire aitaren etxea defendituko dut. Harmak kenduko dizkidate, eta eskuarekin defendituko dut nire aitaren etxea; eskuak ebakiko dizkidate, eta besoarekin defendituko dut nire aitaren etxea; besorik gabe, sorbaldik gabe, bularrik gabe utziko naute, eta arimarekin defendituko dut nire aitaren etxea. Ni hilen naiz, nire arima galduko da, Nire askazia galduko da, baina nire aitaren etxeak iraunen du Zutik. 
Defenderé

la casa de mi padre.

Contra los lobos, contra la sequía,

contra la usura,

contra la justicia,

defenderé

la casa

de mi padre.

Perderé

los ganados,

los huertos,

los pinares;

perderé

los intereses,

las rentas,

los dividendos,

pero defenderé la casa de mi padre.

Me quitarán las armas

y con las manos defenderé

la casa de mi padre;

me cortarán las manos

y con los brazos defenderé

la casa de mi padre;

me dejarán

sin brazos,

sin hombros

$y$ sin pechos,

y con el alma defenderé

la casa de mi padre.

Me moriré,

se perderá mi alma,

se perderá mi prole,

pero la casa de mi padre

seguirá

en pie.

Nire boza mailu bat da poesia beltza

Gizontasun basatiz betetako

Hitz fermua

Zure iltzetan nire ama eztia

kolpeatzen duena

Eta kolpeatzen zaituen bitartean

zure agonia sufritzen duena. 
Mi voz es un martillo negra poesía

Palabra firme y llena

de feroz hombría

Que golpea en tus clavos

dulce madre mía

$Y$ mientras te golpea

sufre tu agonía.

\section{III}

D): Zorrotzako portuan aldarrika

Aleman barkua atrakatu da Zorrotzan.

Zimentua dakar, ehun kiloko sakoetan.

Bien bitartean,

Anton eta Gilen zeuden

zerrarekin

tronko hura erdibitzen.

Sokarekin...

Eztago kablerik...

Bestela...

Tira eta tira,

Orain Anton, gero Gilen, eznaiz hilen,

Gilen.

Hemen euskeraz

ta han erderaz.

Birao egiten zuten,

okerbideak ezpaitaki mintzaerarik, berdin tratatzen baitu

erdalduna

eta

euskalduna.

Arbolaren neurriak hartu nituen.

Antiojuak bustitzen zitzaizkidan.

(Amak gauean pentsatu zuen errekara erori nintzela). Eta esan nuen:

Beti paratuko naiz

gizonaren alde

Gilen.

Anton. 
D): Gritando en el muelle de Zorroza

El barco alemán ha atracado en Zorroza.

Trae cemento en sacos de cien kilos.

Mientras tanto,

estaban Antonio y Guillermo

con la sierra

trenzando un árbol.

Con cuerdas...

No hay cables...

Tira que tira,

Antonio ahora,

Guillermo luego,

cuándo me moriré,

Guillermo.

Aqui en castellano, y alli en vascongado.

juraban.

Porque la injusticia no es políglota

e igual

trata

al castellano

y al vascongado.

Tomé las medidas del tronco.

Se me mojaban los cristales.

(Mi madre por la noche llegó a pensar

que me había caído a la ría). Y dije:

Siempre me pondré

al lado del hombre.

Antonio.

Guillermo.

1

Bart

sobera ardo edan nuen

Barrenkalle Barrenako

tafernarik taferna,

eta etsera ezkero

afaldu gabe

joan nintzen

ohera. 




Anoche bebi demasiado vino en la calle de Barrenkalle de bar en bar, y una vez en casa me fui a la cama sin cenar. Tuve un sueño, que cenaba en el restaurante de Joanito El Cojo ${ }^{31}$ merluza a la koxkera en buena armonía y gran estima con dos amigos. Estos dos amigos eran Cristo y Lenin.

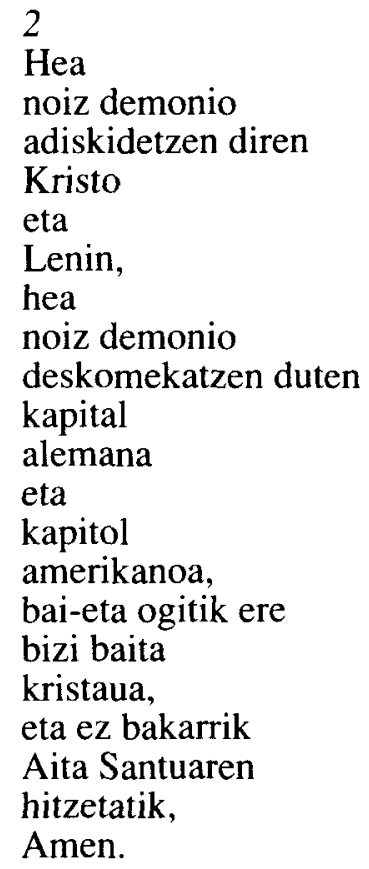

A ver cuando demonios se amigan Cristo y Lenin, y excomulgan el capital alemán y el capitol americano, pues también de pan vive el hombre y no solo de las palabras del Santo Papa, Amen.

3 Restaurante de la Parte Vieja Donostiarra. 


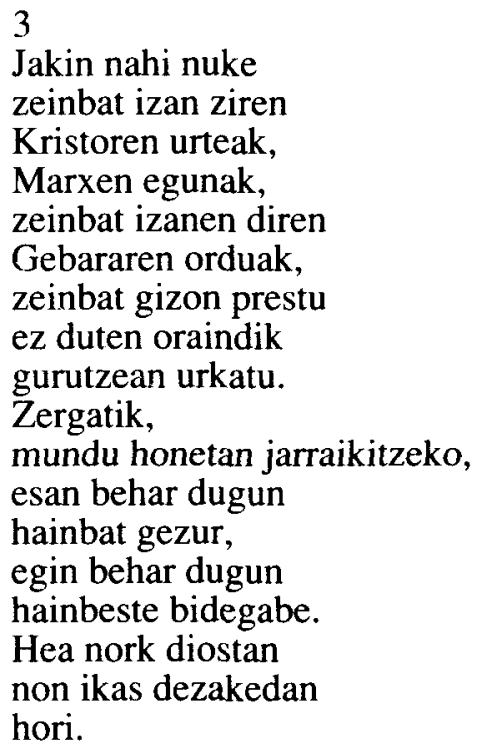

Me gustaría conocer los años de Cristo, los días de Marx, las horas de Gebara y cuántos hombres buenos no han de ahorcar (lit.) todavía en la cruz. Por qué para subsistir en este mundo tenemos que mentir tanto y cometer tantas injusticias. A ver quien me dice donde puedo aprender eso.

\section{$\mathbf{V}$}

RIKARDO ARREGIREN HERIOTZEAGATIK AUHENEZ

(GARIZUMA DEITORAGARRI BAT, HAMAR EGUNEAN ONGI SENTITUA ETA HOGEI, ETA HAMARREAN GAIZKI PENTSATUA).

\section{AUHENAREN SENTIMENDUA}

HAMAR EGUNEAN GORDEA ETA (AZKENEAN) ANDOAINGO ELIZAN LEHERTUA.

Aurtengo uztaren hamarrean

Bilbaoko zerua mitxeletaz estaldurik

agertu zen.

Mila eta bostehun jainkoilo beltz pausatu ziren ene leihoaren kontra,

Mila eta bostehun sorgin bihurri, mila eta bostehun lamia eder. 
Zer berri?

\section{Ekarri?}

Ikusiko, ikusiko.

Heure denbora guztiko.
Aita Kristobal Jaundonearen bederatzien luzea!
Gaur ere ama heriotzeak ongi daduka asea, euskal haragi bortitz-gazteaz agertzen duen gosea.

Zer berri?

Ekarri?

Adituko, adituko.

Eta gainera damuko.

Eta Donostiatik Bilbaora

andre negarreztatu baten garraisia

belarrietara barrena

ebaki zenean,

sasi guztien azpitik

eta

hodei guztien gainetik

itzali ziren

mitxeletak, sorginak, lamiak,

(Mila eta bostehun izan ziren goizalde luze

hartan

kontatu nituenak).

eta barrenaz

min haundi bat jaundu zen,

bildur haundi bat jabetu zen

lotsa haundi bat nagusitu zen.

Done Kristobal xoferra

santu benetan ankerra

hea zeruan zuzentzen duzun

hemengo zeure okerra.

Eta Sasiolako bida-ertzean

neure anaiaren zapata odoleztatuak

ikusi nituencen, zapata haek eneak izan zitezela

eta odol hura

enea izan zedila 
gutiziatzearen indarrez

kezko bola batek itotzen zeuzkidan

biriak.

Sasiolako orena

Rikardo Arregirena

Milaka geunden hartzeko

baina hartu duzu hoberena.

Eta Motrikuko hilerrian

neure anaiaren katabutaren gainean

neure esku zikinak

jarri nituenean,

ni barrenean eta hura kanpoan

egon gintezen gutiziatzearen indarrez,

suzko bola batek lehertu zeuzkidan

begiak.

Hil da Rikardo gurea

Euskeraren errubea:

Geure anaia hil zaigu eta

bizirik nago sugea.

Sasi guztien azpiko eta hodei guztien gaineko leku batean

bilduko gara

berriz

sugea eta usoa.

(Hala agindu - Prometitu eta ordenatu baitzeukun Mateok bere hamargarren kapituluko hamaseigarren bertsetean:

Ecce ego mitto vos sicut oues in medio luporum. Estote ergo prudentes sicut serpentes, et simplices sicut columbae.)

ELEGÍA A LA MUERTE DE RIKARDO ARREGI

(En una Cuaresma lamentable, bien sentida en diez días y mal pensada en treinta)

Sentimiento de la elegía

(Guardada durante diez días y finalmente expresada en la iglesia de Andoain)

El diez de julio de este año apareció el cielo de Bilbao lleno de mariposas, Mil quinientas mariposas negras se posaron en mi ventana 
Mil quinientas brujas traviesas, Mil quinientas lamias hermosas.

¿Alguna novedad?

Ya veremos,

Eso lo dirá el tiempo.

¿Qué larga es la novena del padre San Cristobal!

Hoy también la madre muerte se ha saciado

Con la carne de jóvenes y fuertes vascos.

¿Alguna novedad?

Ya la oiréis,

Y penaréis.

Y cuando el grito de una madre llorosa se escuchó entre Donostia y Bilbao Por debajo de todas las zarzas y por encima de todas la nubes

Se apagaron las mariposas, las brujas y las lamias.

Fueron mil quinientas las que conté en aquella larga mañana.

$Y$ un gran dolor, un gran miedo y una gran vergüenza se apoderaron de mí.

Chofer San Cristobal, menudo cabrón, a ver si arreglas en el cielo la jodienda que has hecho.

$Y$ cuando vi los zapatos sangrientos de mi hermano en el recodo de Sasiola el deseo de que aquellos zapatos fueran mís y aquella sangre mía me ahogaba como una bola de humo los pulmones.

Hora de Sasiola, la de Ricardo Arregi, muchos estábamos antes pero has elegido al mejor.

$Y$ cuando puse mis sucias manos encima del féretro de mi hermano en el cementerio de Motrico, la fuerza del deseo de que estuviera él fuera y yo dentro me reventó como una bola de fuego los ojos.

Ha muerto nuestro Ricardo, la inocencia del euskera. Ha muerto nuestro hermano y vivo yo la culebra.

Nos encontraremos de nuevo la culebra y la paloma en un lugar que está debajo de todas las zarzas y encima de todas la nubes.

Así nos lo prometió Mateo en el versículo dieciséis del capítulo diez:

Ecce ego mitto vos sicut oues in medio luporum. Estote ergo prudentes sicut serpentes, et simplices sicut columbae. 


\section{JOSEBA SARRIONAINDIA}

\section{I}

\section{BITAKORA KAIERA}

Ingurubilean barrena abiatu da bidaztia noiz eta non sartu den oroitzen ez duen arren.

Bidea ingurubila bat dela suposatzen du, gauza berrietan iragandakoen isladak somatzen dituelakotz.

Baina iraganaren isladak ez dira atseginak, izugarriak dira zentrorantz amiltzen dela erakusten deraukotelakotz. Baina ba dea zentrorik?

Ala zabalalderantz amiltzen ote da?

Orduan pentsatzen du gordelekua behar duela eta zokoetan gordetzen du aldizka bere burua. Baina izuak ere bergordelekuetan ezkutatzen dira.

Orduan pentsatzen du noraezean galduko dela eta hari bat behar duela labyrinthoan. Baina zer lokarritan eutsi haria?

Orduan pentsatzen du oroitzapena bederen sostengatu behar duela eta bitakora kaier bat eskribatzen du, ilunabarrero. Hauxe da noraezaren bitakora kaiera, bidaztiak haizerik gabeko itsasoan galerako ekaitza geroago eta gertuago somatzen duen lemazainaren antzera idazten du. Etsipenez eskribatzen du: ez prophetaren antzera, eroaren antzera baizik; ez Jainkoentzat, marionetentzat baizik; marionetak marionetentzat bezala eskribatzen du. Eta bidaztiak badaki batzutan, baina bertzetan ez daki deusere: nor den, bere burua nortzu diren ere. Batzutan pentsatzen du Europan barrena dabilela eulia emakume bilutsiaren gorputzean bezala. Bertzetan bitakora kaiereko orrialde hutsei begira geratzen da Deus ere pentsatu gabe, edo ingurubilak Marrazten.

\section{CUADERNO DE BITACORA}

El viajero se encamina a través de la espiral aunque no recuerda cuándo y dónde penetró.

Supone que el camino tiene forma de espiral, pues en lo nuevo el reflejo adivina lo ya sucedido.

Mas los ecos del pasado no son gratos, provocan terror: muestran que se abate hacia el centro.

¿Pero hay centro acaso? 
¿O se inclina quizá hacia los costados?

Entonces piensa que necesita un refugio y se esconde a ratos por los rincones. Pero también el miedo corre a ocultarse en su misma guarida.

Entonces piensa que se perderá a la deriva y que necesita un hilo en el laberinto. Pero ¿en qué argolla amarrar el hilo? Entonces piensa que al menos el recuerdo podrá sostenerlo y escribe un cuaderno de bitácora, cada atardecer.

Este es un cuaderno de bitácora a la deriva, el viajero escribe como el timonel que, en un mar sin viento, adivina cada vez más cerca la tormenta del desastre.

Escribe con desesperación:

no como el profeta, sino como el loco;

no para los Dioses, sino para las marionetas;

escribe como la marioneta para las marionetas.

$Y$ el viajero sabe a veces, y otras veces nada sabe:

quién es, quiénes son él.

A veces piensa que recorre Europa

como una mosca un cuerpo desnudo de mujer.

Otras veces se queda mirando las páginas en blanco de su cuaderno de bitácora, sin pensar en nada, o dibujando espirales.

II

\section{berrogei IZEN SONETOA egiteko Cuarenta nombres para hacer un soneto}

William Faulkner. Alice Liddell. Buster Keaton. James Joyce. Marilyn Monroe. Stephen Crane. Ambroise Bierce. Marcel Duchamp. Jules Verne. Franz Kafka. Herman Melville. Andre Breton.

Humprey Bogart. Paul Klee. Francois Villon. Jacques Brel. Ezra Pound. Louis Ferdinand Celine.

Nicholas Ray. Dante Alighieri. John Wayne.

Samuel Beckett. Jonathan Swift. John Huston.

Nazim Hikmet. Juliette Greco. Boris Vian, Edgar Allan Poe. Vladimir Nabokov.

Hieronimus Bosch. Bram Stocker. Paul Celan.

Johan Huizinga. Jean Genet. Marcel Schwob.

Edgar Spencer Dogson. Vladimir Holan.

Edwar Lear. Joseph Conrad. Vincent Vang Gogh. 


\title{
III
}

\section{BALBEA}

\author{
hilobiak igurikatzen zaitu \\ bidearen amaieran \\ astiro joan zaitezke \\ atsedenaldiak ere har ditzakezu \\ etsi gabe \\ igurikaturen baitzaitu \\ gaubeldurrez ezpata izterrean \\ zaintzen duen \\ gerlariaren antzera \\ zaitu zaintzen \\ balbeak \\ hilobiak igurikatzen zaituen lekutik \\ eta iristean \\ musua emanen dautzute \\ marrubi erdibitua diren \\ balbearen ezpainek \\ betirako ohantzean \\ etzanaraz orduko
}

\section{LA MUERTE}

te espera la tumba

al final del camino

puedes ir despacio

incluso tomarlo con calma

ya que te esperará

seguro que no te olvida

la muerte te espera

cual guerrero que guarda

su espada entre las piernas

por temor de la noche

desde donde te espera la tumba

y al llegar

los labios de la muerte

fresa partida

te besarán en cuanto yazgas

en el lecho eterno 
IV

\section{ARRATSEKO FADOA}

fadoa arratsean
maitaleen begietako malko doratua
ortze urdina itsaso urdina
urdin lausotua
saudadezko fadoa hiri goibelean
marinelen kalatxori mezularia
itsas hegiko krabelin zimeldua
karrikako pinpilipausa eritua
lema sostengatzen duen brisara
sukaldeen tristura
oherik ez dutenen gordelekua
lehor hegi honetara arribatzean
Ulysesek nigar egin zuen
Nigar kanta hura arratseko fadoa

FADO NOCTURNO

lágrima dorada

en los ojos de los amantes

el fado al anochecer

firmamento azul mar azul

azul nublado

fado de saudade en la oscura ciudad

gaviota mensajera de los marinos

clavel mustio de la costa

mariposa herida de la calle

brisa que sostiene el timón

tristeza de las cocinas

refugio de los sin lecho

al arribar a esta yerma orilla

Ulyses lloró

aquella elegía fado nocturno 


\section{V}

\section{ALBERTO CAEIRO-REN BISITA}

"I know not what / tomorrow will bring" erran zuen Fernando Pessoa-k hil baino egun bat lehenago.

«-Egun enauzu neu etorri

Alberto Caeiro baino» erraiten zautan

Fernando Pessoak, eta mintzaira nahasiz

eta lokarrigabez irauten zuen solasa.

Eguzkiloreek bezala behatzen zituen

hormetan zelai urregorriztatuak

edota muino izarez estaliak

ene begi lausotuek pinturaren bat, izpilua edo horma soila ikusten zuten lekuetan.

Natura ederra eta zaharra dela erraiten zuen, artzainak ardiei begira bezala.

Eta gaua abaildu orduko

euria, eguzkia, ilargia eta etxe ataria aulkia

desiratu eta aldegiten zuen lasai

sonbreiruaren hegala altzatuz.

\section{VISITA DE ALBERTO CAIERO}

"I know not what tomorrow will bring»,

dijo Fernando Pessoa un dia antes de morir.

"- Hoy no he venido yo

sino Alberto Caeiro, me decía

Fernando Pessoa, y seguía su discurso confuso y sin rumbo.

Miraba como los girasoles

En las paredes los campos dorados

o las colinas cubiertas de sábanas

mis ojos cansados alguna pintura,

el espejo o donde veía la pared desnuda.

Decía

como los pastores miran a las ovejas

que la naturaleza

era vieja y bella.

$Y$ en cuanto cae la noche, la lluvia, el sol, la luna

y en el umbral de la casa

el deseado banco

y se iba tranquilo

levantando el ala de su sombrero. 


\section{KOLDO IZAGIRRE URREAGA}

\section{I \\ IZAN NINTZEN POETA HARI LEHEN GUTUNA}

Itsaso mutu bat margotu huen

Heure leihoak itogarri eder bat izan zezan

Itsaso ahantzi bat saskian biltzeko modukoa

Ateondorainoko isila heure bihotzaren eneak

Hezur erratuen abarrotsik gabe entzun ahal izateko

Oinazearen sakona malko mulkotan sinetsi nahirik

Ateondorainoko isila

Ezein untzi fantasmak atreka ez zezan heure ahoan

Bazter odolduen albiste

Heriotzaren zaldia

Lau hanketan zuria

Zazpi pausotan iragaiten du

Gure herriko zubia

Aspaldian agortu dituk itsaso haren iturri gezak

Eta konfesatu nahi baduk heure lerratzea

Zin dagit sinatzen dut ez nuen berehalakoan ikasi

Eskua egunero mozten

Ikasia behar hengoen hitzak ez lukeela hitzetan loratu behar

Poesia balizko erroten erresuma izanik ere

Galdu huen guardasola hura behar huke orain

Elurte honetan idazten jarraitu ahal izateko

Eleak bele bilakatu zaizkiguk eta

Balizko errota guztietarik atera nahi gaituzkek

Auzoan zegok poesia ilunabarrean

Erahildako berri bat ehorzten genuelarik

Azken etxeko leiho ostean

Ukabilen artean ezpainak mugitzen zituen umea

Zazpi pausotan zuria

Heriotzaren zauria

Arinik zatoz nire herrira

Hankagabeko zaldia

Umea leiho ostean dago ezpainka eta mutu

Hilobi berrira etorriko da bihar

Kanposantuek hazitzen dituzte masustarik gozoenak

Eta eskuan estutzen duen kaskiloa

Erakutsiko die lagunei Auzoan zegok

Poesia eta balizko errotak

Abandona erazi nahi zizkigutek

Erreka lehortu zelako aitzakian

Jadanik ez da bustia beleen itzala 
Lehen personan mintzo hintzen zuka heure bihotzari

Eta maitea idatzi huen eta ni aipatu

Bekatuak izateraino ezin biluzitako poemak

Beldur hintzen lurra borobila ez dela aitortzeko

Eta uste huen balizko erroten erresuman hintzela

Eguzki hau ez dela bakarra oihukatzeagatik

Dena esana ez baldin badago ere

Ez baita zilegi dena poesiari ematea

Galdera inuzenteen sasoia joana duk

Zazpi pausoko zubia

Heriotzaren zurià

Ez ote duzu herri neurea

Oker perratu zaldia

Bakea erosirik ere ona dela zioskutek orain dendariek

Noizbait ikasi duk zerrien negarra

Janak isiltzen duela elurte hau manifestaririk gabeko kalea

Bezain triste gelditu zarete kale-poetak

Ametsondoaren desliluraren lainotan

Ereinotz-koroaren ordez negurik ez

Dazaguten adarrak bekokian

Ez haiz gauza gezurra bezain eder esateko egia

\section{PRIMERA CARTA AL POETA QUE FUI}

Pintaste un mar mudo

Para que tu ventana tuviera una bonita horca

Olvidado mar cabía en un cesto

Silencioso hasta tu puerta para que pudieras oir

Los lamentos de tu corazón sin estrépito de errantes huesos

Queriendo creer el sufrimiento por los racimos de lágrimas

Silencioso hasta tu puerta

Para que ningún buque fantasma atracara en tu boca

Mensajero de parajes ensangrentados

Caballo de la muerte

Cuatro patas blancas

En siete pasos cruza

El puente de mi pueblo

Hace tiempo que se agotaron las fuentes de aquel mar

$Y$ si quieres confesar tu error

Lo juro lo afirmo no aprendi a tiempo

A cortarme la mano diariamente

Tendrías que saber que la palabra no debería florecer en palabras

Aunque la poesía sea tierra de molinos imaginarios

Ahora necesitarás el paraguas aquel que perdiste

Para poder seguir escribiendo en esta nevada 
Las palabras se han convertido en cuervos

$Y$ quieren expulsarnos de todos los molinos imaginarios

La poesía está fuera en el atardecer

Mientras enterrábamos un nuevo asesinado

Tras la ventana de la última casa

El niño que movía los labios entre puños

Herida de la muerte

Siete pasos blancos

Llegas ligero a mi pueblo

Caballo cojitranco

Murmura el niño tras la ventana

Mañana vendrá a la nueva tumba

Los cementerios producen las mejores zarzamoras

$Y$ enseñará a sus amigos

El casquillo que aprieta en su puño está

La poesía y quieren echarnos

De los molinos imaginarios

Con la excusa de que el río se secó

Ya no es húmeda la sombra de los cuervos

Hablabas a tu corazón en primera persona

$Y$ escribiste amor y nombraste yo

Poemas que no pudiste desnudar hasta hacerlos pecado

Temías confesar que la tierra no es redonda

$Y$ creías estar en reino de molinos imaginarios

Por gritar que este sol no es único

Aunque no todo esté dicho

No es lícito dar todo a la poesía

Pasó ya el tiempo de las preguntas inocentes

Blancura de la muerte

Puente de siete pasos

Te pregunto pueblo mío

Si herraste bien tu caballo

Ahora los tenderos proclaman que la paz es buena aunque sea comprada Por fin aprendiste que el llanto de los cerdos

Se acalla con pienso esta nevada tan tristes

Como una calle sin manifestantes quedasteis los poetas callejeros

En la nebulosa desilusión post-ensueño

En la frente cornamenta que no sabe de inviernos

En lugar de corona de laurel

No eres capaz de decir verdad tan hermosa como la mentira 


\section{II}

\section{EASTBOURNE-KO FAROA BISTAN}

Eastbourne ez dago Irlandan

Eta faro ingles bat izan litekeen bezain burgesa da

Eastbourneko faroa

$\mathrm{Ez}$ du haren beharrik izanen gure ontziak

Baina hala ere kanta bat merezi du

Eastbourneko faroak

Haren oinarrian jotzen dutenak

Errautsezko olatuak dira

Eastbourne ez dago Galesen

Eta Engels ingles bat izan litekeen bezain burgesa zen

Friedrich Engels

Faro batek adina baizik ez zuen ikasi itsasoaz

Baina hala ere kanta bat merezi du

Friedrich Engelsek

Eastbourneko faroan jotzen dutenak

Haren errautsak dira

Eatsbourne ez dago Eskozian

Eta itsaso ingles bat izan litekeen bezain burgesa da

Eastbourneko itsasoa

Mendebalak ez daki harrotzen bare da beti hemen

Baina hala ere kanta bat merezi du

Eastbourneko itsasoak

Hemen jotzen duten errautsak

Engelsen manifestua dira

Eastbourne ez dago Bretainan

Eta olatu inglesak izan litezkeen bezain burgesak dira

Eastbourneko olatuak

Menturaz ez dute faroa inoiz sunstituko

Baina hala ere kanta bat merezi dute

Eastbourneko olatuek

Etengabean jotzen dute

Engelsen errautsak balira bezala

Eastbourne ez dago Euskal Herrian

Eta errauts inglesak izan litezkeen bezain burgesak dira

Eastbourneko errautsak

Ez dira inoiz berriro sutuko faro egitearren

Baina hala ere kanta bat merezi dute

Eastbourneko errautsek

Olatutan antolatu dira

Itsaso bat direla balekite bezala. 
AVISTANDO EI FARO DE EASTBOURN

Eastbourne no está en Irlanda, El faro de Eastbourne

Es tan burgués como pueda serlo un faro inglés,

Nunca lo necesitará nuestro barco,

Pero aun y todo merece una canción.

El faro de Eastbourne,

El mar que bate sus cimientos

Son olas de cenizas.

Eastbourne no está en Gales,

Friedricb Engels,

Era tan burgués como pueda serlo un Engels inglés,

Del mar no aprendió más que un faro,

Pero aun y todo merece una canción,

Friedrich Engels,

El mar que bate en el faro de Eastbourne,

Son sus cenizas.

Eastbourne no está en Escocia

El mar de Eastbourne

Es tan burgués como pueda serlo un mar inglés

Aquí nunca sopla el vendaval, siempre es calma

Pero aun y todo merece una canción,

El mar de Eastbourne

Las olas que baten aquí

Son el manifiesto de Engels,

Eastbourne no está en Bretaña.

Las olas de Eastbourne

son tan burguesas como puedan serlo las olas inglesas.

Quizá nunca logren tumbar el faro,

Pero aun y todo merecen una canción

Las olas de Easbourne

Baten sin cesar

Como si fueran las cenizas de Engels.

Eastbourne no está en el País Vasco,

Las cenizas de Eastbourne

son tan burguesas como puedan serlo las cenizas inglesas.

Nunca volverán a encenderse para ser faro

Pero aun y todo merecen una canción.

Las cenizas de Eastbourne

Se han organizado en oleaje

Como si supieran que son un mar. 


\section{III}

\section{EZ EZAZUELA EZETZ ESAN}

Oraindik badago zapaldu gabeko uharte bat inor ez da handik itzuli hori da froga

Gure zain zabal etzana

Urrun

Derrotaren minean eta garaitzaren zoroan ere

Ez ezazuela ezetz esan

Nork ez du amets debekatua egin

Borrokatu behar honetarik

Urrun

Naufragiorik zinikoena antolatuko dugu

Tubalaurreko euskaldunak bezala bizi ahal izateko

Ez ezazuela ezetz esan

Aberri guztiez biluzik

Urrun

Eta noizbait lanbroaren erdian azalduko da anker

Uharte urrunenaren bila datorren ontzia

Aberri bat genuela erakusteko

Ez ezazuela ezetz esan

Hurren

\section{NO DIGÁIS QUE NO}

Aun queda una isla sin descubrir

Nadie ha vuelto, esa es la prueba

Esperándonos tumbada

Allí.

En el dolor de la derrota y en la locura de la victoria

No digáis que no.

¿Quién no ha tenido el sueño prohibido?

Olvidarse de este tener que luchar

Alli.

Organizaremos el más cínico naufragio

Para poder vivir como vascos pretubálicos

No digáis que no,

Desnudos de toda patria

Allí. 
$Y$ de la niebla un día surgirá cruel

El barco que busca la isla más lejana,

Para descubrirnos que teníamos una patria

No digáis que no / Allí mismo.

\section{IV}

\section{PORTUKO BLUESA}

Aitortzen dizut portua dela nire aberri bakarra aitortzen dizut portua dela nire aberri bakarra hantxe daukat nik lastre handian oroitzapenen gabarra

Atako banda jo du txalupak umearen begipean atako banda jo du txalupak umearen begipean tanta gozo bat itsasorako hari agur egitean

Ontzi guztiei diosala ta tristura bat bihotzean Ontzi guztiei diosala ta tristura bat bihotzean izen arrotzek herdoil zauriak bidaia gaitzen ostean

Baforearen tximinietan ez da izozten elurrik baforearen tximinietan ez da izozten elurrik portu batean jaioak ez du bide berrien beldurrik

Letrak esaten ikasi nuen ontzi arrotzen branketan letrak esaten ikasi nuen ontzi arrotzen branketan izen gazien ozentasunak munduramina hanketan

Izena brankan ulertezina portukoa berriz txopan ulertezina izena brankan 
portukoa berriz txopan

Rotterdametik zetorren brikak

hondoa jo du arrokan

Txikotak largatzen zirelarik

gaixotzen nintzen saudadez

txikotak largatzen zirelarik

gaixotzen nintzen saudadez

faroen segak oraindik ere

hil egiten nau gaudadez

Draga handiak ezin du hustu

itsas hondoko taberna

draga handiak ezin du hustu

itsas hondoko taberna

itoen loa hautsi du eta

laster joko du galerna

Munduak ongi daki naizela euskaldun seme jatorra munduak ongi daki naizela euskaldun seme jatorra

Txipreko ontzi baten banderaz egina daukat atorra

Zazpi bandera zazpi mintzaje nire aberri bakarra

zazpi itsaso zazpi zohardi

nire aberri nabarra

portuak beti digu amore

kaiak urtzen du aparra

Tristea baita gau ilunean baforearen tutua

tristea baita gau ilunean

baforearen tutua

oroituz egin dizudan blues hau

tristuretan da gautua

\section{BLUS DEL PUERTO}

Confieso que es el puerto

Mi única patria.

Confieso que es el puerto

Mi única patria, 
Alli está en lastre

la gabarra de mis recuerdos.

La barca ha tomado el cargo, Bajo la mirada del niño, La barca ha tomado el largo Bajo la mirada del niño. Una gota dulce hasta el mar En la despedida.

Un adiós a todos los buques, Una tristeza en el corazón, Un adiós a todos los buques, Una tristeza en el corazón. Exóticos nombres heridos de herrumbre a la vuelta del viaje.

En la chimenea del vapor No se hiela la nieve, En la chimenea del vapor No se hiela la nieve.

Quien ha nacido en un puerto

No teme a los caminos.

Aprendí a decir las letras En la proa de los buques. Aprendí a decir las letras En la proa de los buques. La sonoridad de sus nombres movía el mundo bajo mis pies.

Incomprensible nombre en la proa $Y$ el de su puerto a popa,

Incomprensible nombre en la proa $Y$ el de su puerto a popa.

El brik que venía de Rotterdam

Ha tocado fondo en las rocas.

Cuando largaban amarras

Enfermaba de saudade.

Cuando largaban amarras

Enfermaba de saudade.

La guadaña del faro todavía

Me mata de nochade.

La draga nueva no puede vaciar La taberna del fondo.

La draga nueva no puede vaciar 
La taberna del fondo.

Ha roto el sueño de los abogados

Y pronto llegará la galerna.

Bien sabe el mundo que soy

Noble hijo de mi país,

Bien sabe el mundo que soy

Noble hijo de mi país,

Me he hecho una camisa

Con la bandera del barco chipriota.

Siete banderas, siete hablas

Mi única patria.

Siete mares, siete cielos

Mi patria clara,

El puerto siempre nos acoge,

En él muere la resaca,

Triste es en la noche

La sirena de un barco.

Triste es en la noche

La sirena de un barco,

De tristeza oscurece

Este blues de los recuerdos.

\section{LEHORRERATZEN BALDIN BANAIZ}

Ate guztiak joko ditut galdezka

Bide hartuko dut

Basoan barrena abiatuko naiz

Gailurrak iganen ditut

Oihanetan eginen dut lo

Basamortuan fosilduko da nire oinatza

Lehorreratzen baldin banaiz

Lehorreratzen baldin banaiz

Ez nauzu ulertuko

Mito zahar guztiak suntsitu behar genituela oroitaraziko didazu

Eta horregatik hain zuzen

Lehorreratzen baldin banaiz

Malato zuhaitza aurkitu arte zoratuko zaituztet

Aurkituko dut aurkituko dut

Eta aizkora kenduko diot enborrari

Aizkorak emanen dit

Aizkorak bakarrik daki 


\begin{abstract}
Altzaren bihotzaren berri
Lehorreratzen baldin banaiz

Itsasketa hau jarraituko dut
\end{abstract}

\title{
SI DESEMBARCO
}

Llamaré a todas las puertas

Me pondré en camino

Me internaré en el bosque

Subiré a las cumbres

Dormiré en las selvas

En el desierto se fosilizará mi pisada.

Si desembarco

Si desembarco

No me comprenderás

Me harás recordar que juramos romper con todos los viejos mitos.

$Y$ precisamente por eso

Si desembarco

Os volveré locos hasta que descubra el árbol Malato

Lo encontraré, lo encontraré

Y extraeré el hacha de su tronco,

El hacha me dirá,

Sólo el hacha conoce

El corazón del aliso.

Si desembarco

Seguiré navegando. 